\title{
Anadolu Türk Efsanelerinde Cimrilik
}

\author{
Sezai DEMİRTAŞ* \\ Halil BUNSUZ**iD
}

\begin{abstract}
Öz
Kozmopolit bir yapı olan toplumu anlamak için dinî, siyasi, ekonomik, kültürel, sosyal vb. bazı ölçütlere ihtiyaç vardır. Toplum araştırmalarının kültürel boyutunda yer alan sözlü kültür geleneği ve geleneğin önemli bir bölümünü oluşturan halk anlatıları bu ölçütlerden birisidir. Toplumun maddi-manevi değerlerine dair izler taşıyan halk anlatılarında cömertlik, yardımseverlik, doğruluk gibi olumlu davranıș kalıplanı yanında kıskançlık, çekememezlik, kendini beğenmișlik gibi olumsuz davranış biçimleri de kendine yer bulmuştur. Mal biriktirme ve malını paylaşmama hastalığı olarak kısaca tanımlanabilen cimrilik, anlatılarda karşılaşılan olumsuz davranış biçimlerindendir. Türk insanın cimriliğe bakışını halk anlatılarından efsaneler bağlamında inceleme gayesiyle ortaya konulmuş ve folklorun kültürlerdeki eğitimi sağlama, benimsenmiş davranış kalıplarını devam ettirme gibi işlevlerinden yola çıkan bu çalışma kültürel bir okuma çabası niteliği taşımaktadır. Toplum birlikteliğine zarar veren cimriliğin söz konusu kişilerin toplum tarafindan hoş karşılanmaması suretiyle eleştiri konusu hâline getirilmesi ve çeşitli şekillerde ikaz edilerek toplumsal bir farkındalık oluşturulması Anadolu Türk efsanelerinden seçilen örnek metinler vasıtasıyla ortaya konulmaya çalışılmışıtır.
\end{abstract}

Anahtar Kelimeler: Türk Efsaneleri, Anadolu, Cimrilik

\section{Stinginess in Anatolian-Turkish Legends}

\begin{abstract}
In order to understand the cosmopolitan society, religious, political, economic, cultural, society etc. some criteria are needed. Oral culture tradition, which takes place in the cultural dimension of social culture and folk narratives which constitute an important part of the tradition are one of these criteria. In folk narratives which bear traces of the material and moral values of the society, positive behavior patterns such as generosity, benevolence, righteousness as well as negative behavior patterns jealousy, incapacity and self-righteousness have also found their place. Parsimony, which can be defined briefly as the disease of hoarding and not sharing one's property, is one of negative behaviors encountered in narratives. This study, which has been put forward with the aim of examining the Turkish people's view of parsimony in the context of legends and based on the functions of folklore such as providing education in cultures and maintaining the adopted behavioral patterns, has the quality of a cultural reading. Parsimony, which harms the social unity, has been made a subject of criticism by the people in question because it is not welcomed by the society and a social awareness is created by warning in various ways, through sample texts selected from Anatolian Turkish legends.
\end{abstract}

Keywords: Turkish Legends, Anatolia, Stinginess

\section{Giriş}

Toplum, farklı bileşenlerin meydana getirdiği kozmopolit bir yapıdır. Bu yapıyı anlamak için toplumu oluşturan unsurların dinî, siyasi, ekonomik, kültürel, sosyal vb. ölçütlerle birlikte düşünülüp değerlendirilmesi gerekir. Öyle ki toplum araştırmalarında çözülemeyen bir husus, bazen bir gelenek bazen de bir tören veya uygulamanın dikkate alınması sayesinde daha açık ve anlaşılır hâle gelebilmektedir. Sözlü kültür geleneğinin ürünü olan halk anlatılarına bu bakış açısıyla yaklaşıldığında, söz konusu anlatıları oluşturan ve şekillendiren toplumun maddi-manevi değerlerine dair izler bulabilme imkânı vardır. Bu çalısma, mal biriktirme ve malını paylaşmama hastalığı olarak kısaca tanımlanabilen cimriliğe, Türk insanının bakışını Anadolu Türk efsaneleri örnekleminde inceleme gayesiyle ortaya konulmuş bir kültürel okuma çabasıdır.

\section{Olumsuz Bir Davranış Biçimi: Cimrilik}

Adi, alçak, soysuz anlamındaki Farsça cimri kelimesinden Türkçeleştirilerek genellikle pintilik, hasislik anlamında kullanılan cimrilik; İslam ahlak kaynaklarında şuh ve buhl kelimeleriyle ifade edilmiştir. Bunlardan şuh, kişiyi mal mülk edinme hırsına sevk eden harcamalarda bulunmaktan ve yardım etmekten

\footnotetext{
*Arş. Gör. Selçuk Üniversitesi, sezai.demirtas@selcuk.edu.tr

** Dr., halil.bunsuz@hotmail.com

Makalenin Gönderim Tarihi: 04.01.2021; Makalenin Kabul Tarihi: 12.09.2021
} 
alıkoyan bencil bir duygu iken; buhl, bu duygunun etkisiyle iyilik ve cömertlik yapmaktan kaçınma hâlidir (Çağrıc1, 1993a, s. 4).

Cimrilik, geleceğe güvenle bakabilmek amacıyla tutumlu davranan insanların tutumlulukta aşırıya kaçarak mantıksal amaçların dışına çıkması, bir başka ifadeyle kazanma içgüdüsünde bir sapkınlık meydana gelmesidir. Bir nefis hastalığı ve kişilik bozukluğu olan cimrilikte, çeşitli sıkıntılar ve mahcubiyetler göze alınarak biriktirilen para ve malın harcanmaması/harcanamaması söz konusudur. Cimrilik mal sevgisi yanında iktidar arzusu, güven arayışı, hırs, tutku, haset, açgözlülük ve kendini beğenmişlik gibi duygularla yakından ilişkilidir. İleri derecedeki fakirlik korkusu, gelecek kaygısı, mala karşı beslenen aşırı sevgi ve bağllık, yakınlarına iyi bir servet bırakma isteği, benlikte oluşan aşırı hırs sebebiyle insanlara şefkat ve merhamet göstermeyi unutma gibi düşüncelerin etkisiyle ortaya çıan cimrilik, hırs ve bencillik duygusunun da bir yansıması niteliğindedir (Kasapoğlu, 2007, s. 330-336).

Cimrilik denilince yalnızca para toplayıp biriktirmekten oluşan dar anlamda bir kavram değil, bir kimsenin başka bir kişiyi sevindirmeye bir türlü yanaşmadığı yani topluma veya toplumun bireylerine karş1 yakınlık göstermediği, çevresine bir duvar örmek suretiyle kendisine ait sözde hazineleri güvence altına almak istediği bir davranış biçimi de düşünülebilir (Adler, 2018, s. 260). Paylaşımcı anlayışı ortadan kaldıran cimriliğin psikolojik ve sosyal yönleri yanında mülkiyet hakkına dayalı hukuksal bir yönü de vardır. Hukuki olarak özel mülkiyet kapsamında değerlendirilebilecek olan bu paylaşımı reddetme durumu, kişinin hem maddi hem de manevi sahipliğinde olan şeyleri paylaşmaktan kaçınmasıdır. Böyle kişiler, yazılı olmayan hukuk kurallarına (örf, âdet, gelenek, görenek vb.) göre toplum tarafindan dışlansalar da yazılı hukuk kuralları açısından hak sahibi konumunda olduklarından kendilerine dokunulamaz. Buradan hareketle cimrilerin sahip olduklarını kimseyle paylaşmayarak kendilerine ait bir dünya kurgulamaları ve o dünyadaki hâkimiyetlerini koruma düşüncesi, cimriliğin bir özel mülkiyet biçimi olarak da düşünülmesine imkân vermektedir.

Mallarını paylaşmamak suretiyle koruduklarını ve mallarının azalmasını engellediklerini düşünen kişilere bile kazanç sağlamayan cimrilik, olumsuz bir duygu (şuh) ve bu duygunun etkisiyle ortaya çikan olumsuz bir davranış (buhl) biçimidir. Toplum birlikteliğine zarar veren bu davranış, söz konusu kişilerin toplumda hoş karşılanmaması suretiyle eleştiri konusu hâline getirilmekte ve cimriler çeşitli şekillerde ikaz edilerek toplumsal bir farkındalık oluşturulmaya çalışılmaktadır.

Burada ele alınması gereken bir başka husus da cömertliktir. Konunun iki boyutlu bir yaklaşımla ele alınması açısından cimriliğin zıddı bir davranış biçimi olan cömertlik veya eli açıklık üzerinde durulması yararlı olacaktır. Bir kavram olarak eldeki imkânları meşru ölçüler içinde, hiçbir karşllık beklemeden gönüllü olarak başkalarının yararına sunma eğilimini ifade eden cömertlik; israf ile cimriliğin ortasında konumlanan ahlaki bir meziyettir (Özel, 2007, s. 6-7). Cömertlik, İslam ahlak felsefesinin en önemli kavramlarından biri olarak görülmüş; İslam felsefecileri tarafından gerekeni karşılıksız vermek şeklinde tanımlanarak gerçek cömerdin, herhangi bir iyilik veya yarar beklemeksizin karşılıksız olarak veren kişi olduğu ifade edilmiştir (Toksöz, 2016, s. 83-84). Hem Kur'an-1 Kerim hem de hadislerde cömertliğin Allah'in bir sifat1 ve peygamberlerin sahip oldukları üstün bir fazilet olarak kabul edilmesiyle insanlara cimrilik ve israf olarak adlandırılan iki aşırı davranış biçiminden kaçınarak ölçülü davranma, yani eldeki imkânları makul şekilde kullanma düşüncesi telkin edilmektedir. Ayrıca, İslam ahlakına göre cömert olabilmek için başkalarına yardım etmek yeterli görülmemiş, bu yardımın isteyerek ve seve seve yapılması gerektiği ancak bu şekilde cömertliğin insanda bir huy hâline gelebileceği de ifade edilmiştir (Çă̆nıc1, 1993b, s. 72).

Cömertliğin Anadolu Türk kültüründeki yeri araştırıldığında, karşımıza Ahilik kurumu çıkmaktadır. Anadolu'nun Türkler tarafindan fethedilmesi ve Türkleștirilmesinde önemli bir rol oynayan Ahilik teşkilatının çekirdeğini oluşturan değerler arasında cömertlik de yer almaktadır. Öyle ki Ahi sözcügünün kökeniyle ilgili görüşlerden birinin "eli açık, cömert" anlamlarına gelen Türkçe "akı" kelimesine dayandırılması, söz konusu teşkilatın felsefesini ve kurallarını içeren eserlerin adındaki fütüvvet kavramının karşlık beklemeksizin başkalarına yardım etme, cömert ve konuksever olma gibi anlamları da içermesi, cömertliğin fütüvvetnamelerde çok vurgulanan kavramlardan biri olmas1 bu düşünceyi destekler mahiyettedir (Turan \& Gümüss, 2015, s. 598-599). Anadolu coğrafyasının sosyo-kültürel yapısı içerisinde oldukça önemli bir yer tutan Ahilik kurumunun üzerine şekillendiği köşe taşlarından birinin cömertlik ve 
eli açıklık olması, bu coğrafyada yaşayan insanların hem dinî hem de ahlaki bir erdem olan cömertliği benimsemesinde önemli bir rol üstlenmiş olmalıdır. Belki de bu durum, konumuzla ilgili efsanelerde cimriliğe karşı cömertlikten yana taraf tutulmasının ve cimriliğin eleştirilmesinin arka planını meydana getirmektedir.

\section{Efsaneler ve Cimrilik Üzerine}

Gerçek veya hayali belirli bir şahıs, olay veya yer hakkında anlatılan bir hikâye olarak tanımlanabilen efsaneler; anlatıcının tarihî zaman ve coğrafi alan kavramıyla uygunluk gösteren halk anlatılarıdır (Sakaoğlu, 1980, s. 4). Efsaneler; kısa ve inandırıcilık özellikleriyle diğer anlatmalardan kolaylıkla ayrılabilen, sözlü kültürde yaşama direnci gösteren, geçmişten geleceğe taşınması ve yeni metinlerin ortaya çıkması yönüyle bugün de canlıllğını sürdüren ürünlerdir (Gönen, 2015, s. 183). En belirgin özelliği inanış konusu olan efsaneler, anlattıkları şeyler olağanüstü olsa bile gerçekten olmuş gibi kabul edilirler (Boratav 1974, s. 12). Efsanelerdeki bu gerçeklik, objektiflikten uzak sübjektif bir gerçeklik olup efsaneleri anlatan ve dinleyenlerde olayların yaşanmış olduğuna dair bir inanca dayanır (Seyidoğlu, 2005, s.13). Efsanelerdeki bu inanma/inandırma eğiliminin alında yatan etkenlere bakıldığında ise efsane ve halk inançları arasındaki etkileşim göze çarpmaktadır. Halk inancı ve efsane arasındaki ilişki, araştırmacılar tarafindan uzun zamandır üzerinde durulan konulardandır. Bu süreçte ortaya konulan tespitler göz önüne alındı̆̆ında efsanelerin doğal oluşumunda yaşayan halk inançlarının çeşitli tezahürleriyle birlikte iç içe kopmaz bir şekilde yer aldığı ve efsanelerin halk inançlarının bir parçası hâline geldiği, efsanelerin ana işlevinin kanıtlayıcı bir unsur olarak halk inançlarını diri tutmaya hizmet etmek olduğu görülmektedir (Mullen, 2018, s. 211). Konumuzla ilgili efsanelere bu açıdan yaklaşıldığında dinî, ahlaki, vicdani açılardan kaçınılması gereken bir davranışa karşı, toplumun benimsemiş olduğu yaklaşımın yani cimriliğin cezalandırılmaya sebep olabileceği düşüncesinin efsane metinleri aracilığılla toplum hafızasında canlı tutulmaya çalışıldığı düşünülebilir.

Genellikle söze dökülen ve anlatım yoluyla aktarılabilen her şeyi içine alan anlatılar; toplumun "olması gereken" olarak belirlediği düşünce, tutum ve değer yargılarının kendi bakış, anlayış ve yorumlarıyla da birleştirilerek bir kurgu çerçevesinde oluşturulduğu metinlerdir. Bu metinler arasında yer alan efsaneler ise, toplumların kültürlenme sürecinde karşılaşılan sorunlar veya düşülen ikilemlerde yol gösterici, çözüm önerici işlevleriyle teşekkül ettikleri toplumun insanlarını ortak ahlaki değerlerde birleştirme ve onları yönlendirmede etkili anlatılardır (Sever, 2005, s. 91-94). İçerdikleri iletilerle sabırlı olmayı, iyi duygular taşımayı, sayg1 ve sevgiden yana olmayı, her zaman ölçülü davranmayı ögütleyen efsaneler; kıskançlık, hainlik, zalimlik, kin ve nefret gibi olumsuzluklardan kaçınmanın gerekliliğini de vurgulamak suretiyle evrensel bir insan modelinin çizildiği ürünlerdir. Efsaneler aracıllğılla insanların olumlu tutum ve davranışları korumaları, olumsuz tutum ve davranışları terk etmeleri öğütlenirken aynı zamanda toplumun sahip olması gereken değerlerin de altı çizilmiş olur (Süme, 2019, s. 845-851). Efsaneler aracıllı̆̆yla ortaya konulmuş olan bu tavır, folklorun kültürlerdeki eğitimi sağlama ve benimsenmiş davranış kalıplarını devam ettirme işlevlerinin bir yansımasıdır. Böylelikle kültürün yansıması niteliğindeki folklor; gelenekteki ahlaki standartları telkin etme, bunlara uygun davranışlar sergilendiğinde ödüllendirme, aykırı davranışlar sergilendiğinde küçümseme ya da eleştiriyle cezalandırma işlevlerini de yerine getirmiş olmaktadır (Bascom, 2005, s. 140-146).

Çalışmanın çıkış noktası olan cimrilik de ödüllendirilen veya cezalandırılan diğer pek çok olumlu veya olumsuz davranış gibi efsanelerde kendine yer bulmuştur. İnsanın sevilmemesine ve toplum tarafindan dışlanmasına neden olan cimrilikle ilgili toplumsal kabul ve yaklaşımlar sözlü kültür ürünü olan efsanelere ne kadar ve ne şekilde yansımıştır? Efsane metinleri incelendiğinde bu sorunun cevabını bulmak mümkündür. Özellikle şekil değiştirme motifli efsanelerde cimriliğin işlendiği görülür. Bu efsanelerde cimri insanların maruz kaldığ1 sonuçlar dinleyiciye sunulurken bir yönden cimriliğin eleştirisi de yapılır. Dönüşüm ve değişim temeline dayalı bir motif olan şekil değiştirme ile efsanelerin yanı sıra masal ve destanlarda da karşılaşılır. Efsanelerdeki şekil değiştirmeleri diğerlerinden ayıran belirgin özellikler, değişimin kalıcı olması ve dinleyicisini eğitme gayesi taşımasıdır. Örneğin; anlatıcı, çocuğunun altını ekmekle temizleyen kadının çocuğuyla birlikte taş kesildiği efsaneyi anlatarak nimete yapılacak saygısızlığın 
taş kesilmek suretiyle kalıcı bir şekilde cezalandırılacağını ifade ederken ekmeğe, nimete saygıyı dile getirmek ve bu sayede dinleyiciyi o konuda eğitmek ister (Ergun, 1997a, s. 175).

Şekil değiştirme motifli efsanelerde cimrilik konusu bağlamında değerlendirilebilecek davranışlar ve bunların neticesinde yaşanan olaylara oldukça fazla rastlanmaktadır. Bu kapsamdaki efsaneleri, cimrilik yapan kişilerin maruz kaldıkları sonuçlar açısından şu şekilde sınıflandırmak mümkündür.

\subsection{Cimrilik, Taşa Dönüşme Sebebidir}

Canlı veya cansız varlıkların, bulundukları şekil ve yapılarından bazen yapısını bazen de ikisini birden kaybederek taşa dönüşmesi şeklinde tanımlanabilen taş kesilme; şekil değiştirme motifinin en fazla örneği görülen türüdür. Taş kesilmelerin meydana gelmesine zemin hazırlayan kötü huylar arasında yer aldığını gördüğümüz cimrilik ve tamahkârlık, cezalandırılan davranış şekillerindendir (Sakaoğlu, 1980, s. 32, 129131.). Cimrilikle ilgili efsanelerin bu grubunda yer alan örneklerde Hızır, derviş, dilenci vb. tarafindan fazlasıyla sahip olduğu mallardan bir miktar istenen kişilerin cimrice davranması sonucunda taşa döndürülerek cezalandırılması söz konusudur. Bu cezalandırmalarda cimrilik yapan kişiler yanında paylaşılmaktan sakınılan malların da taş kesildiği görülmektedir. Örnek olması açısından iki efsane metnine yer veriyoruz:

Nevşehir'de anlatılan efsanede; köyünde harman yığıp savuran çiftçinin yanına bir dilenci gelir ve biraz buğday ister. Çiftçi, bu kişiyi azarlayarak yanından kovar. Buğday isteyen kişi aslında Hızır'dır ve çiftçiyi sınamak için gelmiştir. Çiftçinin bu cimri tavrı karşısında sinirlenen Hızır "Mademki sen bana buğday vermiyorsun sen de şuracıkta taş kesil!" diyerek çiftçiye beddua eder. Hızır'ın bedduası neticesinde çiftçi yabasıyla birlikte taş kesilir (Tanyu, 2007, s. 157).

Erzurum'da anlatılan bir başka efsanede ise; zengin bir ağanın kızı çok kalabalık bir düğün alayı ile başka bir köye gelin gitmektedir. Yolda gelin alayının karşısına fakir bir adam çıkar. Bu yaşlı ve fakir ihtiyar, Hıdır/Hızır'dır. Ancak gelin alayı onun kim olduğunu bilmemektedir. Hidır karnının aç olduğunu söyleyerek gelin alayından ekmek ister. $O$ zamanki töreye göre; gelin götürülürken fakirlere yardım edilmekte, açlar doyurulmaktadır. Özellikle yolda karşılaşılan herkese kete ikram edilmektedir. Gelin alayı, kendilerinden ekmek isteyen bu ihtiyara kete vermeyince Hıdır da onları kargılayarak "Allah sizleri taş kessin!” der. Hemen o anda gelin alayının hepsi oldukları yerde taş kesilir (Ergun, 1997b, s. 369).

Cimriliğin taş kesilme ile cezalandırıldığı bu efsanelerin benzerlerine Anadolu'nun farklı yerlerinde de rastlamak mümkündür (Sakaoğlu, 1980, s. 131-132; Ergun, 1997a, s. 267-270). Efsane metinleri incelendiğinde, sahip olduğu mallardan bir kısmını paylaşması istenen kişilerin cimrice davranmaları, kendilerinden istekte bulunan kişilerin beddua etmesine bunun sonucu olarak da taşa dönüşmenin gerçekleşmesine neden olmaktadır.

Mal sahibini imtihan için gelen kişi çoğunlukla Hz. Hızır'dır. Sadece burada değil cimriliğin hayvan, göl, dă̆, tepe ve toprağa dönüştürülerek cezalandırıldığı efsanelerde de başrolde olan Hızır, gerek Anadolu gerek Anadolu dışındaki Türklerin efsanelerinde karşılaşılan bir motiftir. Efsanelerde görülen Hızır; halk hikâyesi ve destan gibi halk anlatmalarındakinden farklı olup kahramanlara yardım etmesi yanında günahkâr olanları, fakirlere yardım etmeyenleri, büyüklerine saygısızlık yapanları cezalandırmaktadır (Ergun, 1993, s. 139). Müslüman Türklerin halk inançlarına göre temiz, ahlaklı ve dürüst insanları mükâfatlandırıp kötü huyluları cezalandırma görevine sahip olan Hızır, denemek istediği insanlara çoğu defa çirkin, iğrenç, kaba saba ve bazen de fakir insanlar kilığında görünüp çeşitli isteklerde bulunarak onları imtihan eder. Bu yüzden çoğunlukla kötü davrandıkları insanın Hızır olduğunu anlayan kişilerin duydukları pişmanlığ1 yaşamamak için kullanılan "Her vaktini hazır, her gördüğunnü Hızır bil." sözü insanlar için önemli tavsiye niteliği taşımaktadır (Ocak, 2007, s. 113-114).

\subsection{Cimrilik, Hayvana Dönüşme Sebebidir}

Zor durumdan kurtulma, utanma, cezalandırma gibi sebeplerle insanların kuş, ayı, kaplumbağa, balık vb. hayvanların hâlini aldığ1 dönüşümler, şekil değiştirme motifli efsaneler arasında taş kesilmelerin ardından ikinci sırayı almaktadır. Cimrilik, pintilik, hırsızlık, yalancılık, hileli alışveriş vb. bu dönüşümlerde cezalandırlan kötü huylardandır (Ergun, 1997a, s. 177-180). Cimriliğin cezalandırması ile ilgili iki efsaneyi aşağıda veriyoruz: 
Bingöl'de anlatılan efsaneye göre; eski zamanlarda zengin fakat çok cimri bir ağa vardır. Ağanın malı, mülkü, hayvanları sayılmayacak kadar çoktur. Ağa bir gün koyunlarının yünlerini kırkarken Hızır çıkagelir. Hızır'ın geldiğini gören ağa, "Şimdi benden yün isteyecek." diye yünlerin arkasına saklanıverir. Hızır biraz yün isteyince ağanın çobanı "Yünler ağanındır, ben veremem." diyerek Hızır'ı kovar. Bunun üzerine Hızır, elindeki değnekle yerde yığılmış olan yünlerin altındaki ağaya vurarak "Ağa kalk, ayı kalk!” diye seslenir. Allah'ın hikmetiyle ağa yünlerin altından ayı olarak kalkar, çünkü Hızır'ın bedduasıyla yünler her tarafina yapışmıştır. Ayı şekline giren ağa, ormana doğru kaçmaya başlar (Alptekin, 1993, s. 157).

Mersin'de anlatılan bir efsanede; kadının biri bahçesinde ekmek pişirmektedir. O sırada üstü baş1 perişan, ihtiyar bir adam gelir. Kadından Allah rızası için birazcık ekmek ister. Kadın ekmeği vermez, üstelik hakaretlerle adamı kovar. Meğer ekmek isteyen bu ihtiyar, Hızır'dır. Kadına "Ekmek açtığ1 tahta yatağın, hamur yoğurduğun tekne yorganın olsun, kıyamete kadar bunları taşıyasın, doymak bilmeyesin!" diyerek beddua eder. Hızır'ın bedduası tutar ve kadın bugünkü bildiğimiz kaplumbağaya dönüşür (Erol, 1996, s. 176).

Cimrilik edenlerin dönüştükleri hayvan genellikle ayıdır. Ayı iri cüssesi, çıkardığ1 ses ve sahip olduğu kuvvet dolayısıyla insanları ürküten hatta korkutan bir hayvandır. Efsaneler, birçok hayvanın olduğu gibi ayıların aslının da insan olarak gösterildiği anlatımlarla doludur. İnsanların ayıya dönüşmesi ise cimrilikten veya içinde bulundukları zor bir durumdan kurtulmak istemeleri sebebiyle meydana gelmektedir (Yaldız, 2002, s. 112-114). Orman tanrısı veya orman ruhunun simgesi olarak görülen ayı, Orta ve İç Asya'daki bazı Türk topluluklarında hâlâ yaşayan tözler arasındaki hayvanlardan biridir. Şamanın göğe yaptığı yolculuk sırasında bazen kullandığı yardımcı ruhlardan biri olan ayının İslamiyet’ten sonra daha çok kaba kuvvetin, aptallığın ve kötü insanların simgesine dönüşmeye başladığı görülmektedir (Çoruhlu, 2002, s. 139-140).

İnsanların cimrilik ettikleri için dönüştürüldükleri hayvanlardan biri de kaplumbağadır. Yavaş hareket eden, kabuğunun içinde yaşayan ve uzun ömürlü bir hayvan olarak bilinen kaplumbağanın aslı bir tüccardır. Efsanede anlatıldığına göre bir buğday tüccarı büyük ölçekle alıp küçük ölçekle satmaya başlayınca Allah tarafindan buğday ölçmek için kullandığı büyük ölçeği sırtına küçük ölçeği de karnının altına koyulmak suretiyle cezalandırılmış ve bugünkü kaplumbağa şekline dönüşmüştür. (Sakaoğlu, 2004a, s. 185-186). Cimri erkeklerin ayıya dönüştüğü efsanelerde cimrilik eden bir kadının kaplumbağaya dönüşmesi dikkat çekici bir noktadır. Kaplumbağa; özellikle evini sırtında taşıması ve çok uzun ömürlü bir hayvan olması sebebiyle Türk inancinda uğurlu ve kutsal sayılmış, devletin gücünü, koruyuculuğu, ölümsüzlüğü ve sonsuzluğu simgelemiştir. Bunların dışında kaplumbağanın; bilgelik, mutluluk, başarı, uzun ömür, ebediyet, yeniden doğuş ve diriliş, sabır, azim, umursamazlık, sakinlik, uysallık, asalet, adalet, ululuk, hak yememe, koruma, iyileştirme, annelik, doğurganlık, dayanıklılık, güç, kararllık ve istikrar gibi daha birçok özelliği sembolize ettiğini görmekteyiz (Şimşek, 2016, s. 52). Halkın düşünce dünyası, suçlu bile olsa bir kadını gücün ve kabalığın sembolü olan ayı yerine daha sakin ve kendi hâlinde yaşayan bir hayvana dönüştürmeye layık görerek halk irfanının inceliğini ve ferasetini de ortaya koymuştur.

Cimrilerin cezalandırılırken dönüştürüldükleri başka bir hayvan da balıktır. Yerleşim yerlerinin göle dönüştürülmek suretiyle cimriliğin cezalandırıldığı efsanelerde, kendilerinden istekte bulunan kimselere yardım etmeyen köy, kasaba vb. yerleşim yeri sakinleri bu tavırlarıyla yaşadıkları yerlerin sular altında kalmasına, kendilerinin de buralarda yaşayan balıklara dönüşmelerine neden olmaktadır. Mitoloji ve dinlerde kutsal sayılmış, çeşitli inançlara konu olmuş hayvanlar arasında yer alan balık; Türk kozmolojisinde gök gürültüsü unsurunun hayvan biçimli timsali olması yanında, özellikle göl ve nehir kıyllarında yaşayan Türk topluluklarında bereket, refah ve bolluğun sembolü olarak görülür (Hançerlioğlu, 2000, s.75; Çoruhlu, 2002, s. 144). Yaratılış mitlerinde dünyanın üç balığın üzerinde ve iki balığın arasında kurulmuş bir dengede tasvir edilmesi ise balı̆ga atfedilen kutsallığın bir göstergesi olarak onun insanın yaratılışının, hayatın yeniden doğuşunun, üremenin, bolluk ve bereketin simgesi olmasıyla ilişkilendirilmiştir (Gültepe, 2015, s. 418). Bolluk ve bereket sembolü olarak görülen balık; konumuzla ilgili efsanelerde cimriliğin birey boyutunu aşarak toplu bir cezalandırmanın sonucunda dönüştürülen bir hayvan konumundadır. Cimrilikleri nedeniyle yaşadıkları yerlerin bir felakete maruz kalması ve bu duruma sebep olanların da öldürülme yerine balığa dönüştürülmeleri, söz konusu kişilerin hatalarının bedeli olarak orada yaşamaya mecbur edildiklerini düşündürmektedir. 


\subsection{Cimrilik, Yerleşim Yerlerinin Göle Dönüşme Sebebidir}

Suyla ilgili şekil değiştirme motifli efsanelerin oluşumu çoğunlukla cezalandırma ve zor durumdan kurtulma temeline dayalıdır. Kötü huylar, itaatsizlik, yolcuyu misafir etmeme vb. davranış ve hareketler bunları sergileyen insanların yaşadığı yerlerin göl, nehir veya pınara dönüşmesine neden olmaktadır (Ergun, 1997a, s. 181-182). Aşağıdaki efsaneler cimriliğin yerleşim yerlerinin göle dönüşmesine neden olduğu örneklerdendir:

İzmir'de anlatılan efsaneye göre; Yamanlar Dağı'nın zirvesindeki köye bir gün üstü perişan hâlde bir adam gelir. Köye gelen bu kişi Hızır'dır. Köylülerden yardım isteyen dilenci görünümlü Hızır’a hiç kimse yardım etmez. En sonunda bir kadının evine giden Hızır, kadından biraz ekmek ister. Kadın da "Amca börek yapıyorum pişince vereyim.” der ve pişen börekten Hızır’a verir. Bunun üzerine Hızır "Haydi kızım, buradan gidelim." der ve onlar köyden ayrıldıktan sonra çok geçmeden köy batar. Her yeri suların kapladığı köy göl, köyde yaşayan insanlar ise balığa dönüşürler (Ergun, 1997b, s. 372).

Sivas'ta anlatılan efsanede ise; Hafik Gölü'nün bulunduğu yerde bir zamanlar büyük bir köy vardır. Köye bir gün fakir, kimsesiz ve aç bir yolcu kadın gelir. Bu sırada köylü kadınlar firınlarda ekmek pişirmektedirler. Çok aç olan kadın, firının önünden kadınlara bakarak geçer. Ekmek istemek için yüzü tutmadığından firının önünden birkaç kez geçen kadına, ekmek pişiren kadınlardan hiçbiri ekmek vermez. Çaresiz bir şekilde köyün çıkışına doğru yürüyen kadın bir yandan da "İnşallah, köyünüz sular altında kalır! Ne olurdu bir tane ekmek verseydiniz?” der. Kadın arkasına dönüp baktığında köyün sular içinde kaldığını görür (Demir, 2013, s. 143).

Hayat vericiliği özelliğiyle yaşamın temelini oluşturan suyun ylkma ve yok etme özelliğiyle ön plana çıktığ1 bu efsanelerde, cimriliğin toplu şekilde cezalandırılması söz konusudur. Oluşumları genellikle tektonik, volkanik, vb. olaylara bağlı olan, toprakla çevrili derin ve geniş, tuzlu veya tuzsuz su örtüsü şeklinde tanımlanabilen göller üzerine anlatılan efsanelerin bir grubunu göllerin menşeini/kaynaklarını/oluşumlarını açıklayanlar meydana getirmektedir (Ayva, 2002, s. 254). Konumuzla ilgili efsaneler bu grupta yer almakta olup bahsi geçen anlatmalarda göllerin oluşumu cimrilikle ilişkilendirilmektedir. Göle dönüşen köylerde yaşayanlardan istenen biraz yiyecek, bir parça ekmek aslında onların sınanması için bir vesiledir. Metinler incelendiğinde bu sınamadan genellikle geçilemediği ve cimriliklerinin sonucu olarak köyün insanlarıyla birlikte sular altında kaldıkları görülür. Bu durum cimriliğin bireysel şekilde cezalandırıldığ1 metinlerden farklılık göstermekte olup toplu hâlde bir cezalandırma söz konusudur. Hz. Hızır'ın cezalandırma şekillerinden biri olan yerleşim yerinin sulara gömülmesi ve orada bir su kaynağının (göl) meydana gelmesi, doğal bir afetle cezalandırma niteliği taşımaktadır. Nuh kavminin tufanın meydana getirdiği derin sularda boğulmak suretiyle, Ad kavminin ise günlerce esen şiddetli bir rüzgârla helak edilmeleri peygamber kıssalarında da karşılaşılan bu cezalandırma şeklinin örneklerindendir (Ertuğrul, 2017, s. 171-178). Yukarıdaki efsanede olduğu gibi, bu köylerde az da olsa iyi kalpli, merhametli, cömert insanlar da bulunur. Cimri davrananların aksine kapısını çalan bir kimseyi eli boş gönlü kırık olarak göndermek istemeyen bu insanlar, bencilliğine yenilip ağır şekilde cezalandırılan kişilerin aksine mükâfatlandırılırlar. Sınanmayı geçtikleri için Hızır veya bir derviş tarafından köyü terk etmeleri istenen bu kişilerden, tavsiyeyi dikkate alıp ardına bakmadan köyü terk edenler kurtulurlar. Ancak bu tavsiyeye uymayıp arkalarına bakanlar, meraklarının bedelini taşa dönüşerek (Sakaoğlu, 2004b, s. 180-181) ağır şekilde ödemek zorunda kalmaktadırlar.

\subsection{Cimrilik; Dağ, Tepe veya Toprağa Dönüşme Sebebidir}

Dağ, tepe ve toprağa dönüşmeler şekil değiştirme motifli efsaneler içinde diğerlerine (taş kesilme, hayvana, denize, göle, nehre ve pınara dönüşme) nazaran daha az örneği görülen dönüşümlerdir. Zor durumdan kurtarma ve cezalandırma bu efsanelerin oluşumunda da ana etkenlerdir. İnsanlar veya insan dışındaki varlıklar karşılaştıkları zor bir durumdan kurtarılmak veya cezalandırılmak için dağa, tepeye ve toprağa dönüştürülürler (Ergun, 1997a, s.181). Cimrilik sebebiyle tepe veya toprağa dönüşümlerin meydana geldiği efsanelerden ikisine aşağıda yer veriyoruz:

Ankara'da anlatılan efsanede; vaktiyle çok fakir ve dindar olan bir adam, gece gündüz Allah'a dua ederken günün birinde zengin olursa fakirlere ve düşkünlere yardım edeceğine dair söz verir. Bir gün tarlasını sürerken pulluğun takıldığı yeri kazar ve bir küp altın bulur. Bulduğu hazineyi toprak satın almak 
ve aldığı toprakları işlemek suretiyle değerlendirir ve servetini daha da artırır. Mahsullerini harmanladığı bir gün karşısına çıkan aksakallı bir ihtiyar kendisinden biraz ekin ister. Vermiş olduğu sözleri unutan adam, dilenci görünüşlü bu kişiyi tersler ve harman yerinden kovmaya kalkar. Bu davranışa üzülen yaşlı ihtiyarın ağzından o sırada "Sapın, samanın taş olsun..." bedduası dökülürken ihtiyar da ortadan kaybolur. Bu beddua üzerine bütün harman taş ve kum yığını hâline gelirken yeminini tutmayan adam, bütün malını mülkünü kaybeder ve eskiden beter duruma düşer (Gözaydın, 1978, s. 8287-8288).

Çorum'da anlatılan efsaneye göre; eski zamanlarda harmanını süren bir çiftçi buğdayını eleyerek temizleyeceği sırada karşısında bir dilenci belirir ve çiftçiden Allah rızası için sadaka olarak buğday ister. Çiftçi "Benimle mi çalıştın, ben buğday hâline gelmesi için aylardır çalıştım, sen de hazır malın başına gelerek benden istiyorsun, sizler terlemeden yemeye alışmıssınız." diyerek dilenciye buğday vermez. Dilencinin 1srarlarına ve yalvarmalarına rağmen dilenciyi eli boş gönderir. Bunun üzerine dilenci yerden bir avuç toprak alıp, buğday yığınının üzerine atar. Atmasıyla da buğday yığını toprak olur. Buğday yığını gibi görünen bu tepede ot bile bitmemektedir. Dilenci gibi gelen kişinin ise Hızır olduğu söylenmektedir (Kavcar \& Yardimc1, 1988, s. 40).

Dağa, tepeye veya toprağa dönüşme sebebi olduğu efsanelerde cimrilik, genellikle tarımla ilgilidir. Bu anlatmalarda, harman yerlerinde toplanan mahsullerin şekil değişimine maruz kaldığı görülür. Uzun bir zaman ve emek mahsulü olan ürünlerin harman edildiği sırada Hızır, aksakallı bir ihtiyar veya bir dervişin sınanması ile karşılaşan çiftçiler, cimrilik ederek bencilliklerinin kurbanı olmaktadır. Yukarıdaki efsanelerden ilkinde önceleri fakir olan bir adamın zengin olursa fakirlere, düşkünlere yardım edeceğini ifade ederek her gün dua etmesi neticesinde mal mülk sahibi olması söz konusudur. Yaratıcıya verilmiş bir söz, bir yemin niteliğinde olan bu söylemini unutan çiftçi, zenginliğinin mağrurluğuna kapılarak sözünü tutmaz ve cimriliğinin bedelini her şeyini kaybederek öder. İkinci efsanede ise kendisinden buğday isteyen dilenciye çiftçinin söylediği hakarete varan sözler insan onurunu rencide edicidir. Bu grupta yer alan metinlerde, diğerlerinden farklı olarak cimri kişilerin cezalandırma sırasında bir dönüşüme maruz kalmadıkları sadece mallarının tepeye veya toprağa dönüştüğü görülmektedir.

\section{Sonuç}

Cimrilik, insanlara fayda sağlamayan ve toplumsal teamüllerin benimsemediği bir davranış biçimidir. Türk toplumunun cimrilik ve cimri insanlara dair yaklaşımını Anadolu Türk efsaneleri örnekleminde değerlendiren bu çalışmayla elde edilen sonuçlar şunlardır:

Efsaneler incelendiğinde cimriliğin cezalandırılan bir davranış olduğu görülür. Bu cezalandırma cimrilik yapan kişiler, sahip oldukları mallar ve yaşadıkları yerlerin taşa, hayvana, göle, dağa, tepeye ve toprağa dönüştügü oldukça ağır bir yaptırımdır. Cezalandırmalardan taş kesilme, hayvana ve göle dönüşmelerde kişilerin sahip oldukları şeyler (buğday, koyun yünü, gelin alayında yer alan hayvan ve eşyalar, yaşanılan yerleşim yeri) ile birlikte dönüşüme maruz kalmaları söz konusudur. Bunun yanında dağ, tepe veya toprağın meydana geldiği dönüşümlerde ise mal sahiplerinin değil sadece cimrilik edilip verilmeyen ürünlerin (buğday) dönüştüğü, bunun neticesinde sahip olduklarını kaybeden bu kişilerin de fakirleştirilerek cezalandırılmalarıyla karşılaşılmaktadır. Sonucunda kalıcı şekil değiştirmelerin meydana geldiği bu cezalandırmalar, anlatı yoluyla aktarılan unsurların görsellik kazandırılmasıyla da etkisini artırmaktadır. Tabiatta gördüğü her şeyi anlama ve anlamlandırma ihtiyacı hisseden insanoğlu; bir dağı veya tepeyi, bir gölü, ayı gibi korkutucu ve vahşi bir hayvanı cimrilikle ilişkilendirerek ibretlik hâle getirmiş ve cimriliği kötülerken cömertliği tavsiye etmek suretiyle değerlerin geleceğe aktarımını sağlamıştır.

Cimrilikle ilgili efsanelerin tamamında beddua sonucu dönüşümlerin meydana gelmesi, insanları sınamak için gelen kişinin büyük çoğunlukla Hz. Hızır -bazı efsanelerde Hızır’ın yerini bir derviş, veli, aksakallı ihtiyar gibi kişiler alır- olması, yardım isteyen kişilerin mazlum-mağdur mal sahiplerinin ise zalimgaddar bir konumda bulunması konuya dinî ve ahlaki boyutlar kazandırmaktadır. Koyunlarının yününden, hasadını yaptığı buğdaydan, pişirdiği ekmekten bir parçasını paylaşmak yerine bencilliğine yenik düşen insanların bazen tek başlarına bazen de toplu şekilde üstelik vermedikleri/veremedikleri mallarıyla birlikte cezalandırılması, işlenen ahlaki suçun toplum vicdanındaki karşllı̆ı gibidir. Cimrilik etmeyip elindekini paylaşan kişilerin -ki bu kişiler çoğunlukla kadınlardır- cezalandırılmaktan kurtuldukları görülürken bazen meraklarına yenik düşerek kötü bir sonuca maruz kalmaları da düşündürücü bir konu olarak dikkat 
çekmektedir. Söz konusu efsaneler, sahip olduklarıyla dinî, toplumsal vb. değer yargıları arasında tercih yapması istenen insanlar için bir sınama olması yanında cimrilik ile cömertliğin mücadelesinde toplumun tarafını gösteren bir tavır niteliğindedir.

\section{Extended Abstract}

In order to understand the cosmopolitan society, religious, political, economic, cultural, society etc. some criteria are needed. Oral culture tradition, which takes place in the cultural dimension of social culture and folk narratives which constitute an important part of the tradition are one of these criteria. In folk narratives which bear traces of the material and moral values of the society, positive behavior patterns such as generosity, benevolence, righteousness as well as negative behavior patterns jealousy, incapacity and self-righteousness have also found their place. One of these forms of behavior is parsimony, which can be defined briefly as the disease of hoarding and not sharing one's property. Parsimony is a negative emotion that does not any return and a negative behavior pattern that emerges with the effect of this emotion. This study, which has been put forward with the aim of examining the Turkish people's view of parsimony in the context of legends and based on the functions of folklore such as providing education in cultures and maintaining the adopted behavioral patterns, has the quality of a cultural reading. Legends advising to be patient, to have good feelings, to be respectful and affectionate, to always act in moderation with the messages they contain; emphasizing the necessity of avoiding negativities such as jealousy, treachery, cruelty, hatred and revenge, they are the products of a universal human model. While the values that society should obey are reminded through legends, people are advised to protect their positive attitudes and behaviors and abandon their negative attitudes and behaviors. Parsimony, which is starting point of the study, has found its place in legends like many other positive or negative behaviors. Looking at the reflection of this behavior that causes people to be excluded by the society on the legends, it is seen that parsimony is depicted especially in the legends with metamorphosis motifs. In these legends, while the results suffered by stingy people are presented to the audience, criticism of parsimony is also made. In the legends with metamorphosis motifs, behaviors that can be evaluated in the context of parsimony and the events experienced as a result of them are quite common. It is possible to classify legends in this context in terms of consequences experienced by those who are stingy: Parsimony is the reason turn into stone; parsimony is the reason turn into an animal; parsimony is the reason turn into a lake; parsimony is the reason turn into a mountain, hill or soil. When the legends on the subject are examined, it is seen that parsimony is a punishable behavior. This punishment is a very heavy sanction where people who are stingy or their possessions turn into stone, animal, lake, mountain, hill and soil. Human beings who feel the need to understand and make sense of everything they see in natüre; He associated a mountain or hill, a lake, a frightening and wild animal such as a bear with parsimony and ensured the transfer of values to the future by recommending generosity while denigrating parsimony. The occurence of transformation as a result of curse in all the legends about parsimony, the fact that person who comes to test people is mostly Khidr, the people who seek help are oppressed and the owners are in a cruel position give the issue a religious and moral dimension. The legends in question are a test for people who are asked to choose between what they have and their religious and social value judgments, as well as an attitude that shows the side of the society in the struggle of parsimony and generosity. As a result, with this study, it has been tried to make the parsimony a subject criticism as it is not welcomed by the society and to create a social awareness by warning in various ways, through sample texts selected from Anatolian Turkish legends.

Keywords: Turkish Legends, Anatolia, Stinginess

\section{Kaynakça}

Adler, A. (2018). İnsamı Tanmma Sanatı. Kamuran Şipal (çev.), İstanbul: Say Yayınları.

Alptekin, A. B. (1993). Furat Havzasi Efsaneleri (Metinler). Hatay: Kültür Ofset Basımevi.

Ayva, A. (2002). Türk Dünyasında İnsan Asıllı Göl Efsaneleri. Selçuk Üniversitesi Türkiyat Araștırmalar Dergisi, 12, 251-275.

Bascom, W. R. (2005). Folklorun Dört İşlevi. Ferya Çalış (çev.), İçinde M. Öcal Oğuz, vd. (Ed.), Halkbiliminde Kuramlar ve Yaklassmlar-2 (ss. 125-151), Ankara: Geleneksel Yayınları. 
Boratav, P. N. (1974). Türk Efsaneleri. İsmail Tuğrul Şavkay (çev.), Folklora Doğru, 35, Mayıs-Haziran, 12-19.

Çağrıc1, M. (1993a). Cimrilik. Türkiye Diyanet Vakfi İslâm Ansiklopedisi. (C. 8, ss. 4-5). İstanbul: Türkiye Diyanet Vakfi Yayınları.

Çağric1, M. (1993b). Cömertlik. Türkiye Diyanet Vakfi İslâm Ansiklopedisi. (C. 8, ss. 72-73). İstanbul:

Türkiye Diyanet Vakf1 Yayınları.

Çoruhlu, Y. (2002). Türk Mitolojisinin Anahatlarr. İstanbul: Kabalc1 Yayınları.

Demir, N. (2013). Türk Efsaneleri-I. Ankara: Edge Akademi Yayınları.

Ergun, M. (1997a). Türk Efsanelerinde Değissme Motifi I. Cilt/İnceleme. Ankara: Türk Dil Kurumu Yayınları.

Ergun, M. (1997b). Türk Efsanelerinde Değgsisme Motifi II. Cilt/Metinler. Ankara: Türk Dil Kurumu Yayınlant.

Ergun, P. (1993). Halk Anlatmalarnnda Hı̨̊rr. Yayımlanmamış yüksek lisans tezi, Selçuk Üniversitesi Sosyal Bilimler Enstitüsü Türk Dili ve Edebiyat1 Anabilim Dalı, Konya.

Erol, M. (1996). Taşeli Platosu Efsaneleri (Inceleme-Metinler). Yayımlanmamış yüksek lisans tezi, Erciyes Üniversitesi Sosyal Bilimler Enstitüsü Türk Dili ve Edebiyatı Anabilim Dalı, Kayseri.

Ertuğrul, R. (2017). Kur'an'da Helâk Olan Kavimlerde Suç-Ceza Uyumu-I. Bayburt Üniversitesi İlabiyat Fakültesi Dergisi, 3 (5) , 165-185.

Gönen, S. (2015). Türkçe Kelimelerin Efsane Dünyasında Anlamlandırılması ve Çözümlenmesi. Selçuk Üniversitesi Edebiyat Fakïltesi Dergisi, 33, 181-200.

Gözaydın, N. (1978). Çeçtepe Köyü'nün Taştepe Olması. Türk Folklor Araștırmalar, 18(345), 82878288.

Gültepe, N. (2015). Türk Mitolojisi-Yeni Araştırmalar Işı̆ğnda. İstanbul: Resse Yayınları.

Hançerlioğlu O. (2000). Dünya İnançlar Söそlüğ̈̈. İstanbul: Remzi Kitabevi.

Kasapoğlu, A. (2007). Kur’an'a Göre Cimrilik-Sebepleri, Zararlar1 ve Eğitimi. Cumburiyet Üniversitesi İlabiyat Fakültesi Dergisi, XI/2, 329-364.

Kavcar, Cahit \& Yardımc1, M. (1988). Efsanelerimiz-Inönü Üniversitesi Efsane Derleme Yarısması. Malatya: İnönü Üniversitesi Yayınları.

Mullen, P. B. (2018). Halk İnancı ve Efsane İlişkisi. Ahmet Tacetdin Hallaç (çev.), Folklor/Edebiyat, 24 (96), 211-220. doi.org/10.22559/folklor.397

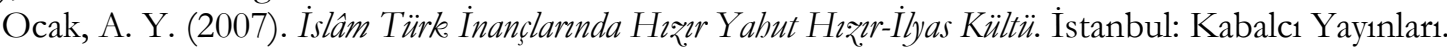

Özel, C. (2007). Kur'an-ı Kerim'de Cömertlik Kavramı, Yayımlanmamış yüksek lisans tezi, Atatürk Üniversitesi Sosyal Bilimler Enstitüsü Temel İslam Bilimleri Anabilim Dalı, Erzurum.

Sakaoğlu, S. (1980). Anadolu-Türk Efsanelerinde Tas Kesilme Motifi ve Bu Efsanelerin Tiph Kataloğu. Ankara:

Kültür Bakanlığ1 Yayınları.

Sakaoğlu, S. (2004a). 101 Anadolu Efsanesi. Ankara: Akçağ Yayınları.

Sakaoğlu, S. (2004b). 101 Türk Efsanesi. Ankara: Akçağ Yayınları.

Sever, M. (2005). Özdeşleşme, İçe Bakış ve Halk Anlatıları. Millî Folklor, 68, 91-95.

Seyidoğlu, B. (2005). Erzurum Efsaneleri, İstanbul: Erzurum Kitaplı̆̆1 Yayınları.

Süme, G. Ç. (2019). "Efsanelerin Eğitimsel İşlevleri." İçinde Esma Şimşek vd. (Ed.), Toroslardan Tanr

Dağlarna Türk Halk Biliminin Ulu Çmar Prof. Dr. Ali Berat Alptekin Armağanı (ss. 843-855), Konya: Kömen Yayınlan1.

Şimşek, E. (2016). Türk Kültüründe Kaplumbağalarla İlgili Efsaneler Üzerine Bir Değerlendirme. Akra Kültür Sanat ve Edebiyat Dergisi, 4(10), 51-63. doi.org/10.31126/akrajournal.328202.

Tanyu, H. (2007). Türklerde Taşla İlgili Inançlar. Ankara: Elips Yayınları.

Toksöz, H. (2016). Fârâbî Düşüncesinde İlâhî Cömertlik (Cûd) ve Adalet (Adl). Diyanet İlmî Dergi, 52

(1), Ocak-Şubat-Mart, 81-100.

Turan, A. \& Gümüş, K. S. (2015). Türk Dünyasında Kültür, Sosyal Dayanışma ve Birlik Köprüsü

Olarak Ahilik Teşkilatı ve Bu Bağlamda Türk Devletlerine Öneriler. Uluslararası Sosyal Araşstrmalar Dergisi, 8 (41), Aralik, 597-612.

Yaldız, A. (2002). Hayvanlarla İlgili Efsaneler, Yayımlanmamış yüksek lisans tezi, Selçuk Üniversitesi Sosyal Bilimler Enstitüsü Türk Dili ve Edebiyatı Anabilim Dalı, Konya. 